\title{
'YOU ALL LOOK THE SAME': Non-Muslim Men who Suffer Islamophobic Hate Crime in the post-Brexit era
}

\begin{abstract}
Existing research on Islamophobic hate crime has examined in detail the verbal, physical and emotional attacks against Muslims. However, the experiences of non-Muslim men who suffer Islamophobic hate crime because they look Muslim remain 'invisible' in both official statistics and empirical research. Drawing on data from qualitative interviews with 20 non-Muslim men based in the United Kingdom, we examined their lived experiences of Islamophobic hate crime. Interviews were transcribed and analysed using thematic analysis. A deductive approach to thematic analysis was adopted to analyse participants' narratives, and six overarching themes were developed: (1) Nature of Islamophobic hate crime; (2) Triggers of Islamophobic hate crime; (3) Impact of Islamophobic hate crime; (4) Reporting incidents, responses and barriers to Islamophobic hate; (5) Victims' coping strategies and (6) Recommendations on tackling the problem. Our findings show that participants experienced Islamophobic hate crime because of 'trigger' events namely the Brexit vote, Donald Trump's presidency as well as ISIS-inspired terrorist attacks in European countries such as France, Germany, Sweden and UK. Participants described being verbally and physically attacked, threatened and harassed as well as their property being damaged. The impacts upon victims included physical, emotional, psychological, and economic damage. These experiences were also damaging to community cohesion and led to polarisation between different communities in the UK.
\end{abstract}

Keywords: Islamophobia; Hate Crimes; Brexit; Trump; Europe

\section{Introduction}

Islamophobic hate crimes towards 'visible' Muslims have increased dramatically in Europe following the terrorist attacks of $9 / 11$ in the US (Organisation for Cooperation and Security in Europe, 2016). In a post-9/11 climate, a particular anxiety towards Muslim 'others' has led to suspicion and outright hostility towards Muslims in the West. Following the terrorist attacks on $7 / 7$, and more recently, the Manchester and London terrorist attacks in May and June 2017, these anxieties have intensified. Muslims in the UK face significantly heightened levels of religious and racial hatred, manifested as hate crimes and incidents. In this context, the rhetoric surrounding Donald Trump's presidency, Brexit and the rise of far right groups throughout Europe have promoted white supremacist ideologies, identities and movements, which reflect Huntington's (1997) 'Clash of Civilizations' thesis. This theory posits that Islam and the West are two monoliths that are 'at war' with each other. The West offers equality, rights, liberties and tolerance whilst 'Islam' offers gender oppression, subordination and violence. To this end, Islamophobic hate crimes 
have increased to a level not seen since 9/11's aftermath. For example, in Germany attacks against recently arrived migrants, many of them refugees coming from predominantly Muslim countries (namely Syria, Afghanistan and Iraq) have increased significantly; more than 3,500 such attacks occurred in 2016, compared with 1,031 in 2015 (OCSE, 2016).

It is important to point out that through forms of racialisation, Islamophobia has led to 'Muslim-looking' individuals also being the victims of this type of hate crime (Ahmad, 2004). Therefore, someone who may have a similar disposition to a Muslim (for example, through appearance, ethnicity or race) is more likely to be seen as an 'ideal' target for Islamophobic hate crimes because of their perceived Muslim identity. Importantly, as our study shows, this can also include people who come from an Atheist, Christian, Hindu or Sikh background. Parvaresh (2014: 1313) observes that "...not only have Middle Eastern Muslims been targeted, but so also have been non-Arabs, non-South Asian Muslims, and non-Muslim Arabs and South Asians, leading all three groups to be racialized into one." In America, the effects of racialisation and people being targeted for their 'Muslim-looking' appearance is not new. Whilst reported incidents of Hindus, Arab Christians and Latinos being targeted is welldocumented, the rise in Islamophobic hate crimes amongst American Sikh men who have continued to be victimised because of the similarity between the Sikh turban and the Muslim cap is growing.

In the UK, whilst attacks against non-Muslim men may not have been welldocumented this does not mean they do not occur. Through the lens of a political and cultural threat, those communities who are mistaken for Muslims face a spike in hate crimes in the UK, particularly in the wake of 'trigger' events such as ISIS-inspired terrorist attacks. For example, in 2015 Zack Davies was sentenced to life imprisonment for attacking Dr Sarandev Singh Bhambra with a claw hammer and a $30 \mathrm{~cm}$-long machete. The attack according to Davies, was for "Lee Rigby" - the British soldier who was murdered by Islamist extremists in May 2013. The fact that Bhambra was not Muslim is significant; he was simply targeted because of his perceived identity of being Muslim. Bhambra's brother stated: "Sarandev was singled out because of the colour of his skin" (Morris, 2014).

The body of Islamophobic hate crime scholarship has grown significantly over the past decade (see, for example, Abbas, 2011; Allen, 2010; Zempi and Awan, 2016). However, what is missing from this literature is a focus on the experiences of non-Muslim individuals who suffer Islamophobic hate crime because they look Muslim. In contrast to a growing scholarship on the nature of Islamophobic hate crime victimisation, there is surprisingly little research that considers the experiences of (non-Muslim) men who suffer Islamophobic hate crime because they are perceived to be Muslim. Drawing from qualitative data elicited through a UK-based study, this article aims to address this gap in the literature. Specifically, we conducted 20 individual, semi-structured interviews 
with a diverse sample of non-Muslim men who have experienced Islamophobic hate crime. Our study therefore advances the hate crime scholarship by examining the experiences of 'invisible' victims of Islamophobic hate crime, that is, men who suffer Islamophobic hate crime on the basis that they look Muslim.

\section{Hate Crime Post Brexit}

Hate crime is a social construct, which is culturally and historically situated. This is evident by the fact that there are different legal definitions across countries and jurisdictions (Wickes et al., 2015). As Jacobs and Potter (1998: 27) point out, understanding the prevalence of hate crime (and the development of appropriate responses to its occurrence) depends on 'how hate crime is conceptualized and defined'. By and large, the consensus view tends to be that hate crimes are criminal acts which are motivated by the offender's bias, prejudice and/or 'hate' towards the victim's identity. In the British context, legislation is centred around the five monitored strands of identity, namely: disability, race, religion, sexual orientation and transgender status (College of Policing, 2014).

That said, it is important to note that the social construction of crime has multiple variations as opposed to a statutory perspective of crime which is often seen through the lens of the mens rea i.e. 'the criminal intention and responsibility' to the actus reus 'the wrongdoing and actual physical aspects of a crime'. Although the legal aspect looks at crime in a linear process, the social construction of crime uses the notion of deviance, and cultural perspectives. The problem with both these competing areas is that crime cannot ever be socially constructed without an application of the legal interpretation of crime. Crime therefore should be viewed in the paradigm of power and society (Foucault, 1977). Within the statutory of construct of crime, crime is therefore viewed on the basis of evidential proofs and the interpretation of legal decisionmaking (Walklate, 2002).

In the UK, hate crime legislation combines a range of penalty-enhancement provisions and offences. For example, the Public Order Act 1986 and the Crime and Disorder Act 1998 create offences specially relating to stirring up racial hatred and racially aggravated offences that relate to assault and harassment. Moreover, the combined nature of offences relate back to the five monitored strands of hate crime i.e. race, religion, gender identity, sexual and disability hate. The UK also adopts the use of victimization surveys in order to measure hate crimes that go unreported. Harassment can include verbal abuse, threats, stalking, online abuse, and bullying. It is a criminal offence under the Protection from Harassment Act 1997 and a person can take civil action in the civil courts. If someone is using the internet to target someone they too can be prosecuted so long as the Crown Prosecution Service view the content of the online communication as constituting threats of violence to the 
person or damage to their property. The communication can constitute verbal harassment, grossly offensive, indecent, obscene, false or coercive behaviour.

However, as McDevitt et al. (2001) observe, 'hate' is absent from the vast majority of hate crimes. Rather, hate crimes may be driven by bias, prejudice, or 'negative feelings held by the offender towards a social group that, in their eyes, have an "outsider status"' (Garland and Chakraborti, 2012: 40). A key element of hate crime is that offenders target potential victims because of their membership of despised 'out-groups'. Referring to the powerful symbolic nature of hate crimes, Chakraborti and Garland (2009) state that such incidents transmit a 'message' not just to the immediate victim but to fellow members of their minority community that reminds them of their 'othered' status: that 'their kind' are not welcome. For authors such as Gerstenfeld (2013) it is the fact that the victim is targeted because of their actual or perceived membership of a social grouping - rather than the presence of any bias or hatred - that is the most significant factor when defining hate crime: it is the attack on their (actual or perceived) identity that sets these acts apart. Implicit in this argument is that these are 'stranger danger' offences, in which the perpetrator selects the victim not because of who they are as an individual but rather because they are part of a despised 'out-group' in the eyes of the aggressor (Perry, 2001).

Islamophobic hate crime scholarship has advanced significantly in a post 9/11 climate. We now have a solid understanding of the motivations associated with hate crime perpetration and the effects of hate crime on victims and fellow group members (Wickes et al., 2017). However, despite important advances in Islamophobic hate crime scholarship, we know little about the experiences of non-Muslim individuals who suffer Islamophobic hate crime because they are perceived to be Muslim. Official data on hate crime only capture the "tip of the iceberg" (Levin, Rabrenovic, Ferraro, Doran, and Methe, 2007: 247), significantly underrepresenting actual levels of hate crime across communities (Wickes et al., 2017). In the case of non-Muslim men who suffer Islamophobic hate crime, using official statistics is even more problematic as high levels of underreporting and errors in police recording render these data largely incomplete (Balboni and McDevitt, 2001).

\section{Research Methods}

The article derives from a qualitative study, which set out to record the experiences of non-Muslim men who suffer Islamophobic hate crime because they look Muslim. Participation to the study was voluntary. The study involved individual, in-depth interviews with 20 non-Muslim men. Qualitative research generates knowledge grounded in human experience (Sandelowski, 2004). Individual, in-depth interviews allow for 'rich' data to be collected with detailed descriptions (Hennink, Hutter and Bailey, 2011). Participants were recruited through engagement with (non-Muslim) religious and secular organisations in 
the UK. In order to ensure participants' anonymity, their real names have been replaced by pseudonyms whilst any personal information that could identify them has been removed. The sample was diverse in terms of age, race/ethnicity and religion. Participants' ages ranged from 19 to 59. In terms of race/ethnicity, participants included those from Asian heritage (fourteen), Black (three), White Other (two) and White British (one). In terms of faith/belief, participants included those of Christian faith (six), Sikh (nine), Hindu (three) and Atheist (two).

The research questions examined: (Q1) the nature of Islamophobic hate crime directed towards non-Muslim men who are perceived to be Muslim; (Q2) the impact of Islamophobic hate crime upon victims and wider communities; (Q3) the coping strategies that were used by victims in response to their experiences of such hostility; (Q4) recommendations on preventing and responding to this hostility. Correspondingly, the interview guide contained a series of open-ended questions related to these research questions. All interviews were undertaken by the authors, and ranged from one to two hours, with an average interview length of one hour. Interviews were digitally recorded and transcribed verbatim.

Interview transcripts were analysed using thematic analysis, a qualitative method used for 'identifying, analysing and reporting patterns (themes) within data' (Braun and Clarke, 2006, p. 79). Thematic analysis is a strategy for organising, describing and making sense of data. Also, it is 'a way of seeing', which highlights the subjective notion of encoding and interpreting data (Boyatzis, 1998, p. 1). Themes refer to specific patterns of meanings found in the data. They may be identified inductively from the raw data or deductively from the existing literature. In the present study, the analysis was driven by the authors' theoretical interest in hate crime as well as the analytic preconceptions regarding the nature, extent and impact of Islamophobic hate crime that has been identified in the literature. This form of thematic analysis is understood as 'deductive' (Joffe, 2012). Ontologically, the thematic analysis in this study was conducted within a realist/essentialist framework on the basis that the authors theorised participants' experiences, views and beliefs at face value whilst the epistemological framework was contextualism, an approach that assumes meaning to be related to the context in which it is produced (Attride-Stirling, 2001). The theoretical approach was enhanced by the authors' engagement with the hate crime literature prior to analysis whereby early reading informed them about the nature, extent and impact of Islamophobic hate crime.

The authors used Braun and Clarke's (2006) six-phase approach to thematic analysis. The first step included the researchers familiarising themselves with the data by repeated, active reading of the transcripts and noting down initial ideas for coding. The second step involved generating initial codes across the entire data set, collating data relevant to each code. Coding was performed 
electronically through copying extracts of data from individual transcripts and collating each code together in a separate file on the computer. The third step included searching for themes. The authors examined the codes and collated data to identify significant broader patterns of meaning (i.e. collating data relevant to each candidate theme). The fourth step included reviewing and refining the candidate themes to ensure that there were clear distinctions between the final themes. Candidate themes were refined, split, combined or discarded. Final themes were clearly linked back to the research questions, but each theme was distinct. The fifth step included defining and naming themes. The authors wrote a detailed analysis of each theme. This included making sense of the content of the data extracts presented, and considering whether they agreed with, or contradicted the existing literature. At this stage, the authors chose an informative name for each theme. The final step included producing the current article. Six overarching themes were developed: (1) Nature of Islamophobic hate crime; (2) Triggers of Islamophobic hate crime; (3) Impact of Islamophobic hate crime; (4) Reporting Incidents, responses and barriers to Islamophobic hate; (5) Victims' coping strategies and (6) Recommendations on tackling the problem. The authors selected illustrative data extracts in order to provide sufficient evidence of the themes within the data. In the analysis provided in the next section, both shorter quotes within the narrative and longer block quotes are included, and all quotes are accompanied by participant's gender, race, and any other characteristic relevant to their experiences of victimisation.

Attride-Stirling (2001) argue that to be accepted as trustworthy, qualitative researchers must demonstrate that data analysis has been conducted in a precise, consistent, and exhaustive manner through recording, systematising, and disclosing the methods of analysis with enough detail to enable the reader to determine whether the process is credible. According to Nowell et al., (2017), it is crucial that researchers conduct theoretically and methodologically sound thematic analysis research that aims to create sensitive, insightful, rich, and trustworthy research findings. Indeed, the authors' aim was to meet the trustworthiness criteria outlined by Lincoln and Guba (1985). To this end, the authors conducted the research in a rigorous and methodical manner to yield meaningful and useful results. Before outlining how this was achieved, it is important to note that the concept of trustworthiness entails the criteria of credibility, transferability, dependability, and confirmability (to parallel the conventional quantitative assessment criteria of validity and reliability) (Lincoln and Guba, 1985). Specifically, credibility addresses the 'fit' between participants' views and the researchers' representation of them (Tobin and Begley, 2004). Transferability refers to the generalizability of inquiry; in qualitative research, this relates only to case-to-case transfer (Tobin and Begley, 2004). Although it is not possible for researchers to know the sites that may wish to transfer the findings; yet, they should provide thick descriptions, so 
that those who seek to transfer the findings to their own site can judge transferability (Nowell et al., 2017). To achieve dependability, researchers can ensure the research process is logical, traceable, and clearly documented (Tobin and Begley, 2004). According to Lincoln and Guba (1985), confirmability is established when credibility, transferability, and dependability are all achieved. Confirmability is concerned with establishing that the findings are clearly derived from the data (Tobin and Begley, 2004). The table below highlights how the authors addressed Lincoln and Guba's (1985) criteria for trustworthiness during each phase of thematic analysis.

Table 1. Establishing trustworthiness during each phase of thematic analysis

\begin{tabular}{|c|c|}
\hline Phases of thematic analysis & $\begin{array}{l}\text { Means of Establishing } \\
\text { Trustworthiness }\end{array}$ \\
\hline $\begin{array}{l}\text { Phase 1: Familiarising self with the } \\
\text { data }\end{array}$ & $\begin{array}{l}\text { - Archived all records of the raw data } \\
\text { - Prolonged engagement with data } \\
\text { - Documented initial analytic } \\
\text { interests and thoughts, } \\
\text { interpretations, and questions in } \\
\text { reflexive journal }\end{array}$ \\
\hline Phase 2: Generating initial codes & $\begin{array}{l}\text { - Peer debriefing } \\
\text { - Reflexive writing } \\
\text { - Audit trail of code generation }\end{array}$ \\
\hline Phase 3: Searching for themes & $\begin{array}{l}\text { - Thematic map to make sense of } \\
\text { connections between themes } \\
\text { - Kept detailed notes about } \\
\text { development and hierarchies of } \\
\text { concepts and themes }\end{array}$ \\
\hline Phase 4: Reviewing themes & $\begin{array}{l}\text { - Themes and sub-themes vetted by } \\
\text { both authors during team meetings } \\
\text { - Returned to raw data to ensure that } \\
\text { the themes reflected participants' } \\
\text { voice (i.e. tested for referential } \\
\text { adequacy) }\end{array}$ \\
\hline $\begin{array}{l}\text { Phase 5: Defining and naming } \\
\text { themes }\end{array}$ & $\begin{array}{l}\text { - Team meetings to discuss themes } \\
\text { and reach consensus on overarching } \\
\text { themes }\end{array}$ \\
\hline Phase 6: Producing the report & $\begin{array}{l}\text {-Described process of coding and } \\
\text { analysis in detail } \\
\text {-Thick descriptions of context } \\
\text {-Reported on theoretical, } \\
\text { methodological, and analytical } \\
\text { choices throughout the entire study }\end{array}$ \\
\hline
\end{tabular}




\section{Analysis}

A deductive approach to thematic analysis was adopted to analyse participants' narratives, and six overarching themes were developed: (1) Nature of Islamophobic hate crime; (2) Triggers of Islamophobic hate crime; (3) Impact of Islamophobic hate crime; (4) Reporting incidents, responses and barriers to Islamophobic hate; (5) Victims' coping strategies and (6) Recommendations on tackling the problem. Due to word restrictions, the first four themes will be explored and discussed in this paper.

\section{Theme: Nature of Islamophobic Hate Crimes}

Islamophobic language used by the offender(s) was the most common reported indicator for participants that their victimisation was motivated by the perpetrators' hostility towards Islam and Muslims. Participants described incidents where they were verbally attacked in public places, although in some cases, the verbal abuse had escalated to physical abuse, as indicated in the comments below.

I've had experiences where people have made comments, for example, "you p*i Muslim" or swearing about Prophet Mohammed. They think I'm Muslim because of my skin colour but I'm not Muslim, I'm Sikh. (Deepak, 45, Indian, Sikh)

Another driver overtook my car shouting "You've killed innocent people, go back to Syria, you ISIS terrorist". (Richard, 28, White, Atheist)

I was walking late at night, and someone came from behind. I had a rucksack on my back. I felt a knock on my back, and when I looked back, I saw that a knife had gone through it. Luckily, I had some clothes in the rucksack so they had stopped it going any further. (Parminder, 59, Indian, Sikh)

In addition to verbal and physical abuse, Islamophobic hate crimes often moved beyond the victim and in fact targeted the individual's home or business. Some participants described how their homes, business or places of work were targeted because they were perceived to be Muslim.

I live on a rough estate. I had dog excrement shoved through the mailbox. They also threw paint over my door. (Paul, 37, White, Atheist)

Slogans including "Muzzies out" were painted across the exterior walls of my house. The graffiti was in large white letters. A week 
later, I received anti-Muslim hate letter in the post. My parents were concerned for my safety, given the threats made on the letter. (Joshua, 21, Pakistani, Christian Catholic)

They smashed the windows of my shop. The shop name sounds Muslim, and we are the only Asian shop in the high street, that's why I think, we also look like Muslims and my kids wear the turban too. (Taranjeet, 36, Asian, Sikh)

In addition to being verbally and/or physically attacked in the 'real' world, participants also reported experiencing Islamophobic hate crime in the cyber world, as indicated in the comments below.

For me it's more online than offline. People leave horrible comments like "Go home, you $f^{\star \star \star} k$ ing Muslim" on my Facebook. (Parminder, 59, Indian, Sikh)

I suffer hate crime when I'm online on social media. I was on Twitter and I shared a post about Muslims giving money for charity after the terrorist attack in London and I got abuse hurled at me. I have my picture on my twitter profile. People started commenting on the tweet and saying "you $f^{* * *}$ ing asshole $f^{* * *}$ off with the terrorists, you terrorist, Bin Laden”. (Govinda, 42, Indian, Hindu)

\section{Theme: Triggers to Islamophobic hate crime}

In lights of these experiences of Islamophobic victimisation, participants differentiated between 'external' and 'personal' factors that contributed to their experiences of Islamophobic hate crime. External factors included issues unrelated to them (such as Brexit, Trump and ISIS-inspired terrorist events) whereas personal factors entailed aspects of their appearance that contributed to them being perceived as Muslim. Awan and Zempi (2015) note how 'trigger' events of local, national and international significance can influence the prevalence and severity of hate incidents both in the online and offline world, thereby heightening the vulnerability of 'other' groups and communities. In June 2016, the British public took part in a historic vote to decide on whether the UK should remain in the European Union (EU). The vote, which was held on Thursday 23rd June 2016, resulted in England voting in favour for Brexit, by $53.4 \%$ to $46.6 \%$. At the same time as England voted to leave, the UK witnessed a sudden surge in hate crimes. This led to an increase of $42 \%$ in England and Wales since the Brexit result was announced. In this study, participants reported that they experienced a spike in Islamophobic hate crimes after the Brexit vote. 
The Brexit campaign has promoted an atmosphere where it's fine to be racist, Islamophobic and xenophobic. (Deepak, 45, Indian, Sikh)

I have seen a spike in abuse since the UK voted to leave the EU last year. (Paul, 37, White, Atheist)

On Facebook, someone wrote on my timeline "Shouldn't you be on a plane back to Pakistan? We voted for you being out." (Joshua, 21, Pakistani, Christian Catholic)

Indeed, evidence shows that the EU referendum result of June 2016 was a catalyst for an unprecedented surge in reports of hate crime (BBC News, 2017). A majority of police forces in England and Wales saw record levels of hate crimes in the first full three months following the EU referendum. More than 14,000 hate crimes were recorded between July and September 2016 whilst in 10 forces, the number of suspected hate crimes increased by more than $50 \%$, compared to the previous three months. Similarly, the 2016 Presidential Election in the US, has resulted in worrying spikes in hate crime, especially towards (actual and perceived) Muslims (Southern Poverty Law Centre, 2016). Along similar lines, participants also noted how the Trump administration and its stance towards Muslims had promoted Islamophobic sentiments both nationally and globally.

I've noticed that abuse has increased on social media after Trump coming into power. People are now very open on social media about their hatred. Before Trump, people were more reserved. I'm on a lot of sites having discussions with people, and I find that racism and Islamophobia are very prevalent. Trump's views are very extreme like banning Muslims to enter US. (Richard, 28, White, Atheist)

Trump really changed everything, didn't he? $\mathrm{He}$ is so blatantly racist and anti-Muslim that he changed the climate completely. Brexit added to that and then you have the rise of Marie Le Pen and farright groups everywhere in Europe like France, Germany, Netherlands and Austria. The rise of the far-right is now a global thing, their voices are heard more and more, and acted upon, which is really worrying. (Paul, 37, White, Atheist)

Furthermore, participants noted how ISIS-inspired terrorist events in European countries such as France, Germany, Sweden and UK have led to an increase in Islamophobic hate crime attacks in the UK. 
I've noticed a rise in abuse when there is a terrorist attack. Sadly the overall situation is deteriorating. Islamophobia is having an increasing impact on the lives of Asian men who look Muslim. The hatred that lies behind Islamophobia is spreading. (Deepak, 45, Indian, Sikh)

My 15-year old son was recently verbally abused by a gang of youths. They shouted to his face: "you're a terrorist". The incident took place following the Manchester terrorist bombings. (Jayesh, 40, Indian, Sikh)

I've experienced a rise in hostility after the Manchester terrorist bombings and the London Bridge attack. l've witnessed the same trend after the Lee Rigby murder and the Charlie Hebdo terrorist attacks. (Raj, 39, Indian, Hindu)

With respect to personal factors, some participants argued that their beard and/or turban (for Sikh men) were key aspects of their appearance that led to being perceived to be Muslim, as indicated in the following quotes.

On a daily basis, I get people on the streets calling me 'traitor' and 'Ginger Terrorist' because of my beard. They think that I'm Muslim, a convert to Islam but I'm not, I'm an atheist. Having a beard is part of my style, not for any religious reasons. (Paul, 37, White, Atheist)

Because of being a Sikh man with a beard and turban, people see me as a terrorist. (Dalvinder, 22, Indian, Sikh)

In addition, participants argued that other aspects of their identity such as their skin colour and gender contributed to being perceived as Muslim and thus, being victimised.

It's my skin colour and also because I have a little beard, I think that's why they think "he must be a Muslim". As I am a male too, and all these Islamist terrorists are males too, that's probably why they look at me and target me too. (Nick, 24, Afro-Caribbean, Christian)

Being held at the airport consistently and being treated as a suspect. Because I'm mixed race and I look Muslim, I always get stopped and get abuse at airports. The association of looking like a Muslim is the problem for me. Someone actually asked me "why do you look like a Muslim? Why are you denying it?" (Samuel, 58, African-Caribbean, Christian) 
Having explored the nature and motivations of these attacks, the following section highlights the multiple layers of harm associated with Islamophobic hate crimes including emotional damage, psychological scars, physical violence as well as the escalation of social tensions between different religious communities.

\section{Theme: Impacts of Islamophobic hate crime}

Participants reported that they suffered anxiety and panic attacks, depression, difficulty sleeping, fear, loss of confidence and feelings of vulnerability, physical illness, loss of income and employment as a result of their experiences of Islamophobic hate crime. Participants unanimously reported feeling fearful for their personal safety in public.

I've experienced more attacks and intimidation after the terror attacks in London and Manchester [...] I don't feel secure in the UK anymore. The UK has become a much scarier place. (Joshua, 21, Pakistani, Christian Catholic)

People have been calling me names on Twitter like "You're a $p^{*{ }^{*} i}$ $c^{* \star} t$ ". I have also been threatened on Facebook like "Today is the day we get rid of the likes of you!" I fear for my safety when I read this. (Vinesh, 32, Indian, Hindu)

In some cases, participants had to leave their job (particularly those working in the night-time economy) as they feared for their safety; this had implications for them financially.

The most horrific incident was when a group of white lads punched me and broke my teeth on my way back from work. While they were punching me, they shouted 'all Muslims should be killed'. I was working in a chip shop at the time. I have now left my job since this incident happened. (Richard, 28, White, Atheist)

Clearly, participants feared for their safety although this sense of vulnerability depended upon the geographical area in which they were located. For example, some participants argued that they felt safer in diverse cities in the UK such as Birmingham. In contrast, in less diverse areas, the sense of vulnerability as well as the risk of attack was perceived to be significantly higher. Thus participants argued that they avoided going to predominantly 'white' areas. This infers that the impact of fear of future attacks had restricted participants' freedom of movement. 
Whenever I consider going to a place where there are less people of colour, I feel literally very scared. That's why I love Birmingham. You see people from all over the world here. I feel safer here. (Dalvinder, 22, Indian, Sikh)

At the same time though, the geographical area where participants lived was also a factor that identified them as Muslims and thus enhanced their vulnerability to both online and offline attacks. For example, one of our participants, Richard (28, White, Atheist) argued that people thought that he was a Muslim convert because he lived in a Muslim neighbourhood. He noted that people could see his location on his profile on social media, and this meant that he was targeted (both online and offline) because of his perceived affiliation to Islam. Richard moved out of this area to prevent being targeted in the future. Other participants also referred to examples of behavioural changes. They argued that they tried to be aware of their surroundings, minimise the time they were in public, and/or avoid certain areas.

It worried me when someone tried to stab me. But I can't let this affect me. I minimise how much I go out but if it's going to happen, it's going to happen. But I try not to let it affect me. I do what I want to do but I try to be aware of my surroundings, more now than I used to. (Parminder, 59, Indian, Sikh)

Other participants changed their appearance in order to protect themselves from future abuse. For some individuals, shaving their beard and/or taking their turban off seemed to be a promising strategy for helping them to erase the perceived source of their vulnerability, and therefore reduce the risk of future attacks. But despite taking measures to prevent future victimisation, feelings of insecurity were exacerbated by the fact that these incidents usually took place in public places in view of people passing-by who did not intervene to help them. Considering the serious limitations of official data on hate crimes, bystanders could be an important source of information on the level of hate crime occurring in the community (Wickes et al., 2017). However, the fact that no one would normally intervene to help victims had culminated in feelings of loneliness and isolation, as indicated in the following quotes.

I was verbally abused by another passenger on the bus who branded me an "ISIS terrorist" while passengers looked on without intervening. In another incident, I had 'Brexit' yelled in my face. I feel very lonely. No one has come to my assistance or even console me. (Mark, 40, White, Christian Orthodox)

When I was younger, I was chased by a gang of skinheads. I was beaten up. I had stones thrown at me. I had incidents where people 
tried to knock my turban off. No one has ever come to my defense.

(Parminder, 59, Indian, Sikh)

Furthermore, a key finding amongst our participants was the fact that they constantly felt the need to prove their identity, and differentiate themselves from Islam and Muslims. They explained that this was an attempt to prevent future victimisation; however, this was also emotionally draining for our participants. As the following quotes indicate, the need to constantly 'prove their identity' had resulted in a cumulative experience of emotional burnout over time.

We [Sikhs and Muslims] are different people. People see us through eyes of Muslims but we are not. Because of my beard, I need to explain why I have this and that I'm not Muslim. I think 'why do I need to prove who I am?' Every second, every minute, every day I have to prove myself. (Dalvinder, 22, Indian, Sikh)

Finally, participants noted that fellow members of their communities were also affected by their personal experiences of Islamophobic hate crime. For example, participants argued that other members of their communities were fearful for their safety because they knew that they themselves were equally vulnerable to verbal and physical abuse as (perceived) Muslims. Participants argued that some members of their communities were angry, upset and frustrated as they felt it was unfair to be targeted because of their perceived affiliation with Islam. This had led to feelings of polarisation and hostility between the Muslim community and other religious groups, particularly Sikhs and Hindus. In the words of one of our participants: 'Communities are polarised'. Similar views were expressed below.

This is a divided society. Some Sikhs blame Muslims for the abuse they get. We are facing a huge challenge is cohesion in our communities. Local councils need to do more to bring the Muslim community and the Sikh community together. (Parminder, 59, Indian, Sikh)

People think that Muslims are the same as ISIS. I know that the Muslim community are doing the best they can internally to fight ISIS but it's not enough. (Mark, 40, White, Christian Orthodox)

\section{Theme: Reporting Incidents, Responses and Barriers to Islamophobic Hate}

With respect to reporting their experiences of Islamophobic hate crime to the police, participants argued that they did not feel satisfied with the way the police had dealt with their case. In most cases, participants felt that the police were dismissive of their case. 
The last incident included being verbally abused by a taxi driver in Oxford. When I got into the car, he said "Get out! I don't put Muslims in my car". I said I'm not Muslim but then he came out and dragged me out the car. I reported it to the police but they said that the CCTV outside the train station did not work this so it was my word against his. They did not believe me and the case was closed. (Mark, 40, White, Christian Orthodox)

At the same time though, some participants argued that they would not normally report their experiences to the police. Indeed, as the following quotes demonstrate, lack of confidence in the police was prevalent amongst our participants.

I don't have confidence in local police. I don't think I will be listened to, I don't think I will be taken seriously. Offenders will not be brought to justice. (Raj, 39, Indian, Hindu)

Once I punched a man who called me a 'Muslim child groomer'. I didn't report it to the police but the man who I punched did (laughing). The police were rubbish. They said it was my fault for punching him. (Paul, 37, White, Atheist)

To complicate matters further, participants who had experienced online abuse decided to take action and report their abusers to social media providers namely Twitter and Facebook. However, they unanimously reported that 'nothing happens' when they report their abusers to the social media providers.

On Twitter I just report the accounts that verbally abuse me but I still see those people on there so I'm confused why Twitter fails to remove people. (Govinda, 42, Indian, Hindu)

My profile on Facebook is open. Other users downloaded my pictures, wrote 'Ginger Terrorist' on them and then reposted them on Facebook tagging me along. I reported these accounts to Facebook but nothing happened. I have now made my account private. (Paul, 37, White, Atheist)

\section{Discussion}

As the preceding discussion demonstrates, participants experienced Islamophobic hate crime in the 'real' world but also in the cyber world because of 'trigger' events namely the Brexit vote, Donald Trump's presidency as well as ISIS-inspired terrorist attacks in European countries. Also, key aspects of participants' identity such as appearance, race/ethnicity, and gender 
contributed to them being perceived as Muslim, and thus suffering Islamophobic hate crime. That said, it is important to note that hate crimes cause greater harm than equivalent crimes without bias intent (Iganski, 2001). Compared with non-hate victims, hate crime victims more commonly report feeling unsafe and fear future victimisation (McDevitt et al., 2001). CraigHenderson and Sloan argued that the range of negative emotions experienced by victims of racist crime are 'qualitatively distinct' from the emotions experienced by victims of parallel crimes (2003: 482). For example, Iganski and Lagou (2014) note that, compared with victims of parallel crimes, victims of hate crime are more likely to report experiencing: higher levels depression and withdrawal; anxiety and nervousness; loss of confidence; anger; increased sleep difficulties; difficulty concentrating; fear and reduced feelings of safety. Correspondingly, the research data in our study illustrated the emotional, psychological, behavioural, physical and financial impacts of experiencing offline and/or online Islamophobic hate crime upon our participants.

Each hate crime has many victims in respect of the vicarious, or terroristic, impacts they can have upon targeted communities (Iganski, 2001). The harms of hate crime extend beyond the immediate victim to negatively impact the victim's reference community. This is a problem that affects not only the victim but the wider community to which victims belong. Hate crimes are more harmful to the community than non-hate crimes on the basis that they undermine tolerance and social inclusion by conveying an "outsider" status of the victim and fellow group members to the broader community (Wickes et al., 2017). Indeed, hate crime is a unique form of offending. The aim of the offender is to send a message to the victim and the victim's group members that they are not welcome in the community (King, Messner, and Baller, 2009). Correspondingly, the impact of hate crime extends even further, affecting all members of the community in question. Therefore, hate crimes are considered more damaging to the social fabric of society than parallel crimes as they attack collective values, disrupt social harmony, and fuel intolerance for diversity (Wickes et al., 2017). Indeed, participants in our study argued that Islamophobic hate crimes were damaging, not only to individual victims, but also to community cohesion and led to polarisation between different communities in the UK.

Victims of hate crime can often minimise their experiences, because of their everyday experiences of suffering hate crimes. The normalisation of targeted harassment and violence can also lead to non-reporting of such incidents to the police. Indeed, our participants argued that they were unlikely to report such incidents to the police (but even when they did report it, their case was likely to be dismissed). Underreporting of hate crime is also a common factor when taking into account official statistics. Victims of hate crime are less likely to report incidents for a variety of reasons such as anxiety, mental health related problems, fear that they will not be taken seriously, previous unsatisfactory 
experiences, a lack of confidence in the police, and fear they will be become the victims of repeat offences (Berzins et al., 2003). Clement et al., (2011) argue that victims will not report hate crimes because of the overall trauma of the incident and that fact that they fear being humiliated or targeted again because of the power relationship perpetrators often have over their victims. It is important to note that not all aspects of hate crime or hate incidents should solely be reported to the police. In fact, the range of responses from our participants means that some incidents we argue should be reported to third party reporting centres, victim support, citizens advice bureau, social media companies and local community organisations. As hate crimes are message crimes that go beyond the individual we argue that community impact statements should also be adopted as a way to enhance reporting of hate crimes and also providing victims with aftercare following an incident.

\section{Conclusion}

There is a dearth of empirical research exploring the experiences of nonMuslim men who are especially vulnerable to Islamophobic hate bias, prejudice and hate on the basis that they can be identified as 'Muslim-looking'. Drawing from qualitative interviews with 20 individuals, the study addressed this gap by exploring their lived experiences. Individual, semi-structured interviews were transcribed and analysed using thematic analysis (Braun and Clarke, 2006, 2013). The ontological framework was realism (focuses on reporting an assumed reality evident in the data) and the broad theoretical (epistemological) framework was contextualism, an approach that assumes meaning to be related to the context in which it is produced. Thematic analysis was used deductively; thus, coding and theme development were directed by existing concepts or ideas. These ontological and epistemological positions tie in with the authors' aim to stay close to the participants' worldview and to this end, view the world through their eyes (Braun, Clarke, \& Rance, 2014). Six overarching themes were developed: (1) Nature of Islamophobic hate crime; (2) Triggers of Islamophobic hate crime; (3) Impact of Islamophobic hate crime; (4) Reporting incidents, responses and barriers to Islamophobic hate; (5) Victims' coping strategies and (6) Recommendations on tackling the problem. Due to word restrictions, only the first four themes were explored and discussed in this paper.

Hate crimes send a message to the victim and the victim's group members that they are neither safe nor welcome in the community (Perry, 2014). On the strength of the present evidence, it is clear that Islamophobic hate crimes caused significant damage to the emotional, psychological and physical wellbeing of our participants, and reinforced the sense of isolation and powerlessness typically felt within groups who encounter targeted hostility as a routine feature of being 'different'. A number of third party reporting centres have now emerged, which provide an alternative system for victims to report 
incidents. The use of a third party reporting mechanism is meant to make things easier for victims of hate crime. However, in our study, participants were not aware of the range of these resources. We argue that for victims, better signage and visible posters displayed across public platforms, could have a direct and indirect impact on helping dismantle some of the barriers towards reporting hate crimes. In 2015, the British Prime Minister, Theresa May announced that all police forces in England and Wales must record Islamophobic hate crimes as a separate category within their central recording systems. It was envisaged that this would mean a more accurate picture could be ascertained in regards incidents of Islamophobic hate crimes. In our study, as the victims were not Muslim, questions about how the police might record such incidents were less clear. For example, some participants noted how they would like the incident to be recorded as a religious hate crime and not necessarily as an Islamophobic incident. This does therefore raise further questions about reporting and recording incidents of hate crime.

At present, not all of the protected monitored strands are treated the same. This can be problematic for victims because they may view that if they report a hate crime it will not be taken seriously. This is also highlighted by the fact that certain types of hate crimes may attract longer sentencing than others (Walters et al. 2017). Combined with the fact that some police forces record misogyny and alternative subcultures as a form of hate crime and others do not leaves victims with a confused picture. We argue that all forms of hate crime should be treated the same and that until sentencing is more consistent victims are likely to feel less confidence within the criminal justice system. For example, the Crime Survey for England and Wales state that $48 \%$ of hate crimes are reported to the police (Corcoran et al. 2015).

We know that 'trigger' events have also significantly impacted upon hate crimes in schools in England following incidents such as the Brexit vote and the election of the US president Donald Trump. For example, in the middle of the Brexit referendum campaign in May, the number of reports of hate crimes and hate incidents in schools rose by $89 \%$ compared to the same month in 2015. Moreover, during the summer and autumn terms in 2016 - when the Brexit referendum took place and Donald Trump won the US presidential election - the number of hate crimes and hate incidents in schools increased by $48 \%$, compared with the same period in 2015 (Busby, 2017). As a result, we argue that schools must adopt a strong campaign in relation to understanding hate crimes. We feel that this is best situated within the training of teachers and also within the school curriculum that children must follow. This should go beyond core values to actual core actions about respect, dignity and tolerance. 


\section{References}

Abbas T (2011) Islamophobia in the UK: Historical and Contemporary Political and Media Discourses in the Framing of a Twenty-First century Anti-Muslim Racism. In: Esposito JL and Kalin I (eds) Islamophobia: The Challenge of Pluralism in the 21st Century. Oxford: Oxford University Press.

Allen C (2010) Islamophobia. Surrey: Ashgate.

Ahmad NM (2004) A rage shared by law: Post-9/11 racial violence as crimes of passion. California Law Review 92: 1261-1330.

Attride-Stirling J (2001) Thematic networks: an analytic tool for qualitative research. Qualitative Research 1 (3): 385-405.

Awan, I and Zempi, I. (2015) Virtual and Physical World Anti-Muslim Hate Crime, The British Journal of Criminology, 57 (2): 362-380.

Balboni JM and McDevitt J (2001) Hate crime reporting: Understanding police officer perceptions, departmental protocol, and the role of the victim: Is there such a thing as a "love" crime? Justice Research and Policy 3: 1-28.

BBC News (2017) Record hate crimes after EU Referendum. Available at: www.bbc.co.uk/news/amp/38976087 (accessed 28 January 2018).

Berzins KM, Petch A and Atkinson JM (2003) Prevalence and experience of harassment of people with mental health problems living in the community. British Journal of Psychiatry 183: 526-533.

Boyatzis RE (1998) Transforming qualitative information: thematic analysis and code development. Thousand Oaks, CA: Sage.

Busby, E. (2017) Exclusive: School hate crimes spike following Brexit and Trump votes (Online) Available at: https://www.tes.com/news/exclusiveschool-hate-crimes-spike-following-brexit-and-trump-votes (accessed on 18 July 2017).

Braun V and Clarke V (2006). Using thematic analysis in psychology. Qualitative Research in Psychology 3 (2): 77-101.

Braun V and Clarke V (2013) Successful qualitative research: A practical guide for beginners. London: Sage. 
Braun V, Clarke V and Rance N (2014) How to use thematic analysis with interview data. In: Vossler A and Moller NP (eds.) The counselling \& psychotherapy research handbook. London: Sage, 183-197.

Chakraborti N and Garland J (2009) Hate Crime, London: Sage.

College of Policing (2014) Hate Crime Operational Guidance. Available at: www.report it.org.uk/files/hate_crime_operational_guidance.pdf (accessed 12 January 2018).

Corcoran, H., Lader, D. and Smith, K. (2015). Hate Crime, England and Wales, 2014/15 (Online) Available at:

https://assets.publishing.service.gov.uk/government/uploads/system/uploads/ attachment data/file/467366/hosb0515.pdf (Accessed 18 July 2018).

Clement S, Brohan E, Sayce L, Pool J and Thornicroft G (2011) Disability hate crime and targeted violence and hostility: A mental health and discrimination perspective. Journal of Mental Health 20 (3): 219-225.

Craig-Henderson K and Sloan LR (2003) After the hate: helping psychologists help victims of racist hate crime. Clinical Psychology: Science and Practice 10 (4): 481-490.

Foucault M (1977) Truth and Power. In: Gordon C (ed.) Power/Knowledge. Brighton: Harvester, pp. 107-133.

Garland J and Chakraborti N (2012) Divided by a common concept? Assessing the implications of different conceptualizations of hate crime in the European Union. European Journal of Criminology 9 (1): 38-51.

Gerstenfeld P (2013) Hate crimes: Causes, controls, and controversies. London, England: Sage.

Hennink M, Hutter I and Bailey A (2011) Qualitative Research Methods. London: Sage.

Huntington SP (1997) The Clash of Civilizations and the Remarking of World Order. New York: Touchstone.

Iganski P (2001) Hate Crimes Hurt More. American Behavioural Scientist 45 (4): 626-638. 
Iganski P and Lagou S (2014) The personal injuries of "hate crime." In: Hall N, Corb A, Giannasi P and Grieve J (eds) The Routledge international handbook on hate crime. New York, NY: Routledge, pp. 34-46.

Jacobs J and Kimberly P (1998) Hate Crimes: Criminal Law and Identity Politics. New York: Cambridge University Press.

Joffe H (2012) Thematic analysis. In: Harper D and Thomson AR (eds) Qualitative research methods in mental health and psychotherapy.

Chichester: John Wiley and Sons, 209-223.

King R, Messner S and Baller R (2009) Contemporary hate crimes, law enforcement, and the legacy of racial violence. American Sociological Review 74: 291-315.

Levin J, Rabrenovic G, Ferraro V, Doran T and Methe D (2007) When a crime committed by a teenager becomes a hate crime results from two studies.

American Behavioral Scientist 51: 246-257.

Lincoln Y and Guba EG (1985) Naturalistic inquiry. Newbury Park, CA: Sage.

McDevitt J, Balboni J, Garcia L and Gu J (2001) Consequences for victims a comparison of bias- and non-bias-motivated assaults. American Behavioral Scientist 45: 697-713.

Morris S (2015) Nazi-obsessed loner guilty of attempted murder of dentist in racist attack, The Guardian. Available at: https://www.theguardian.com/uknews/2015/jun/25/zack-davies-racist-guilty-attempted-murder-dentist (accessed 26 January 2018).

Nowell LS, Norris JM, White DE and Moules NJ (2017) Thematic analysis: Striving to meet the trustworthiness criteria. International Journal of Qualitative Methods 16 (1): 1-13.

Parvaresh R (2014) Prayer for Relief: Anti-Muslim Discrimination as Racial Discrimination. Southern California Law Review 87 (5): 1287-1317.

Perry B (2001) In the name of hate: Understanding hate crimes. New York, NY: Routledge.

Perry B (2014) Exploring the community impacts of hate crime. In: Hall N, Corb A, Giannasi P and Grieve J (eds) The Routledge international handbook on hate crime. New York, NY: Routledge, pp. 47-57. 
OSCE (2016) Racism and Xenophobia. Available at:

http://hatecrime.osce.org/what-hate-crime/racism-and-xenophobia (accessed 26 January 2018).

Sandelowski M (2004) Using qualitative research Qualitative Health Research 14: 1366-1386.

Southern Poverty Law Centre (2016) The Trump effect: The impact of the 2016 presidential election on our nation's schools. Available at:

www.splcenter.org/20161128/trump-effectimpact-2016-presidential-electionour-nations-schools (accessed 28 January 2018).

Tobin GA and Begley CM (2004) Methodological rigour within a qualitative framework. Journal of Advanced Nursing 48: 388-396.

Walklate, S. (2002) 'Perspectives in Criminological Theory' In Jewkes, Y. \& Letherby, G. (eds.) Criminology: A Reader, (Sage Publications, Thousand Oaks).

Walters M, Wiedlitzka S, Owusu-Bempah A and Goodall K (2017) Hate Crime and the Legal Process (Online) Available at:

http://sro.sussex.ac.uk/70598/3/FINAL\%20REPORT\%20-

\%20HATE\%20CRIME\%20AND\%20THE\%20LEGAL\%20PROCESS.pdf (accessed on 18 July 2018).

Wickes RL, Pickering S, Mason G, Maher JM and McCulloch J (2015) From hate to prejudice: Does the new terminology of prejudice motivated crime change perceptions and reporting actions? British Journal of Criminology 56 (2): 239-255.

Wickes R, Sydes M, Benier K and Higginson A (2016) "Seeing" hate crime in the community: Do resident perceptions of hate crime align with self-reported victimization? Crime and Delinquency 63(7): 875-896. 